\title{
Pengaruh Kedalaman Pemasangan Vertical Drains dengan Pemodelan Tanah di Laboratorium
}

\author{
Azzahra Nadia Putri' ${ }^{1}$, Istiatun ${ }^{2)}$ \\ 1,2) Jurusan Teknik Sipil, Politeknik Negeri Jakarta, \\ Jl. Prof. DR. G.A. Siwabessy, Kampus Baru UI Depok, 16424. \\ Email: azzahranadptr@gmail.com, istiatun@sipil.pnj.ac.id
}

\begin{abstract}
Abstrak
Pada umumnya tanah lunak memiliki daya dukung yang kurang baik, juga mudah memampat bila menerima beban. Pemampatan yang terjadi akan sangat lama karena tanah lunak memiliki sifat pemampatan yang sangat kecil. Untuk mempercepat pemampatan yang terjadi dipasang vertical drains. Kedalaman vertical drains yang dipasang akan berpengaruh terhadap derajat konsolidasi yang terjadi pada tanah lunak. Untuk mengetahui pengaruh tersebut dilakukan uji pemodelan di laboratorium menggunakan bak uji berukuran $60 \mathrm{~cm}$ x $80 \mathrm{~cm}$ x 90 $\mathrm{cm}$ dengan tinggi lapisan tanah adalah $50 \mathrm{~cm}$. Kedalaman vertical drains yang dipasang adalah $50 \mathrm{~cm}, 40 \mathrm{~cm}, 30$ $\mathrm{cm}$ dan $20 \mathrm{~cm}$. Tanah yang digunakan adalah tanah lunak Hambalang dengan klasifikasi menurut USCS,termasuk lanau (MH) dan menurut AASTHO yaitu A-7-5. Pemberian beban preloading dan waktu pembebanan pada setiap variasi kedalaman vertical drains adalah sama. Besarnya penurunan dicatat dan dibandingkan dengan penurunan total untuk mengetahui derajat konsolidasi yang dicapai. Nilai derajat konsolidasi yang diperoleh pada kedalaman pemasangan vertical drains $50 \mathrm{~cm}, 40 \mathrm{~cm}, 30 \mathrm{~cm}$, dan $20 \mathrm{~cm}$ adalah 47,75\%; 47,58\%; 37,40\%; dan 34,06\%. Dapat disimpulkan bahwa semakin dalam pemasangan vertical drains, maka semaiki besar nilai derajat konsolidasi yang dicapai.
\end{abstract}

Kata kunci: derajat konsolidasi, penurunan, preloading, tanah lunak, vertical drains.

\begin{abstract}
In general, soft soil has a poor bearing capacity, and it is easy to compress when there is load on top of it. The compression that occurs will take a very long time because soft soil has very little compression properties. To speed up the compression that occurs, a vertical drains is installed. The depth of the vertical drains that is installed will affect degree of consolidation that occurs in soft soil. To determine the effects of vertical drains, we do the test by making a modeling soil using a test tube measuring $60 \mathrm{~cm} \times 80 \mathrm{~cm} \times 90 \mathrm{~cm}$ with a soil layer height of 50 $\mathrm{cm}$. The variations of vertical drains that installed are $50 \mathrm{~cm}, 40 \mathrm{~cm}, 30 \mathrm{~cm}$ and $20 \mathrm{~cm}$. The soil used is soft soil from Hambalang with classification according to USCS, the soil is elastic silt (MH) and according to AASTH, the soil is A-7-5. The preloading method and the time we take for each variations of vertical drains depth are the same. The result of soil lowering at that time, compared to the value of total lowering to see the degree of consolidation achieved. The degree values obtained at the vertical drains installation depth of $50 \mathrm{~cm}, 40 \mathrm{~cm}, 30 \mathrm{~cm}$, and $20 \mathrm{~cm}$ are $47.75 \% ; 47.58 \% ; 37.40 \%$; and $34.06 \%$. It can be concluded that the deeper the vertical drains is installed, the greater the value of the degree of consolidation achieved.
\end{abstract}

Keywords: degree of consolidation, preloading, settlement, soft soil, vertical drains.

\section{PENDAHULUAN}

Pada bidang konstruksi sipil, tanah mempunyai peran yang sangat penting sebagai penunjang utama pembangunan (Pratama, 2015). Permasalahan yang terjadi pada proses pembangunan konstruksi berlangsung, umumnya diakibatkan oleh tanak lunak yang memiliki koefisien permeabilitas yang rendah dan daya dukung yang kurang baik (Suroso dkk., 2008). Sifat tanah yang kurang menguntungkan ini, sangat berpotensi mengakibatkan terjadinya penurunan tanah pada saat proses pembangunan sedang berlangsung yang dapat menyebabkan terjadinya kegagalan struktur (Gunawan, 2014). Penurunan yang terjadi memakan waktu yang sangat2 lama. Oleh karena itu, pada pembangunan konstruksi yang didirikan diatas tanah lunak, melakukan percepatan penurunan konsolidasi sangat perlu dilakukan.

Pada saat tanah dengan permeabilitas rendah mengalami berkurangnya volume secara perlahan akibat berkurangnya angka pori tanah, hal ini yang disebut dengan proses konsolidasi (Puspita, 2017). Untuk mempercepat waktu konsolidasi, dilakukan pembebanan awal 
(preloading) sebelum beban bangunan asli berdiri di atas tanah tersebut (Dian Utami dkk., 2018). Untuk mempercepat proses preloading, dikombinasikan dengan pemasangan vertical drains yang berfungsi untuk memperpendek lintasan aliran air dalam tanah (Juniarto, 2011).

Berdasarkan latar belakang tersebut, perlu diketahui jenis dari tanah yang akan digunakan. Untuk mengetahui sifat fisis tanah didasarkan oleh komposisi dari tanah tersebut, dimana tanah lunak memiliki dua jenis yaitu lapisan lempung dan lapisan lanau (Fathurrozi, 2016). Dengan diketahuinya tanah lunak tersebut, penelitian dilakukan dengan membuat pemodelan tanah pada bak uji yang dipasang vertical drains dengan variasi kedalaman berbeda-beda menggunakan bahan dari geotekstil yang kemudian dilakukan preloading selama waktu 96 jam, akan menghasilkan penurunan atau pemampatan pada tanah.

Tujuan dari penelitian ini, antara lain mengetahui klasifikasi tanah dari Hambalang, untuk mengetahui besar penurunan tanah total akibat beban preloading secara teoritis, untuk mengetahui nilai derajat konsolidasi yang diperoleh akibat beban preloading dengan kedalaman vertical drains yang berbeda pada waktu yang telah ditentukan berdasarkan pemodelan di laboratorium dan mengetahui pengaruh dari kedalaman vertical drains terhadap derajat konsolidasi pada waktu yang telah ditentukan berdasarkan pengujian di laboratorium.

Sesuai dengan tujuan, penelitian ini memiliki manfaat antara lain memberikan wawasan dan pengetahuan bagi penulis dan pembaca khususnya tentang penerapan mata kuliah geoteknik, yaitu: perbaikan tanah, maupun ilmu-ilmu teknik sipil pada umumnya dan menjadi bahan pertimbangan bagi pihak terkait sebagai solusi alternatif dalam perbaikan tanah lunak pada suatu rencana pembangunan.

\section{METODE}

\section{Lokasi Penelitian}

Lokasi dilakukannya penelitian ini dapat dilihat di Gambar 1, lokasinya adalah di Laboratorium Mekanika Tanah, Teknik Sipil Politeknik Negeri Jakarta, Depok, Jawa Barat.

Tanah yang digunakan untuk melakukan penelitian diambil di Hambalang pada kedalaman 0,5 - $1 \mathrm{~m}$. Tanah asli Hambalang digunakan untuk dilakukan pengujian sifat fisis untuk mengetahui kadar air, nilai batas cair, nilai batas plastis, gradasi dan berat jenis yang dibutuhkan untuk memastikan klasifikasi tanah tersebut.

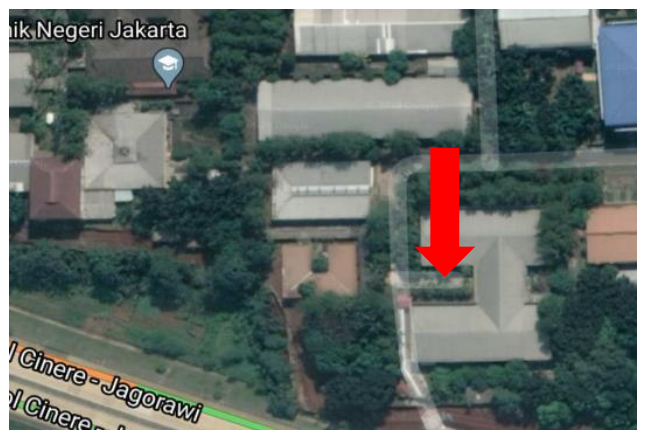

Gambar 1. Peta lokasi penelitian berlangsung

\section{Tahapan Penelitian}

Penelitian dilakukan berdasarkan tahapan berikut :

1. Persiapan alat dan bahan penelitian

2. Pengambilan tanah asli dan tanah untuk membuat pemodelan dari Hambalang

3. Pengujian sampel tanah asli Hambalang, yaitu pengujian sifat fisis dan mekanis, antara lain :
a. Kadar air
b. Berat jenis
c. Gradasi
d. Hidrometer
e. Atterberg
f. Konsolidasi

4. Melakukan penelitian konsolidasi pada tanah lunak Penelitian kali ini, dilakukan dengan membuat pemodelan tanah pada bak uji berukuran $60 \mathrm{~cm}$ x $80 \mathrm{~cm} \times 90 \mathrm{~cm}$, seperti pada Gambar 2. Tahapan pembuatan model tersebut adalah :

1) Masukkan tanah dari dasar bak uji sampai ketinggian $50 \mathrm{~cm}$.

2) Memasang piezometer dan lakukan fase penjenuhan.

3) Pasang vertical drains pola segiempat dengan variasi kedalaman $20 \mathrm{~cm}$.

4) Memasang lapisan separator.

5) Masukkan pasir diatas tanah setebal $20 \mathrm{~cm}$ sebagai preloading, baca dial dengan waktu preloading selama 96 jam.

6) Melakukan model berikutnya dengan langkah yang sama dengan 
kedalaman vertical drains $30 \mathrm{~cm}$, kemudian $40 \mathrm{~cm}$ dan terakhir $50 \mathrm{~cm}$.

\section{Analisis data}

Dilakukan analisis data dengan menggunakan data yang diperoleh pada pengujian tanah asli dan pengujian pada pemodelan tanah.

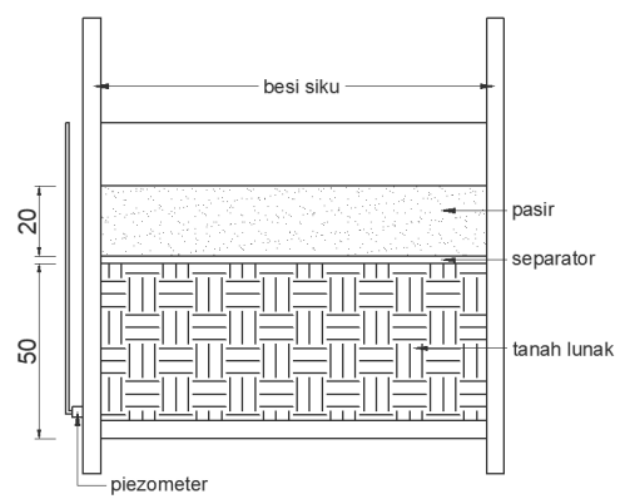

Gambar 2. Ilustrasi keadaan bak uji

\section{HASIL DAN PEMBAHASAN}

\section{Klasifikasi Tanah Asli Hambalang}

Data sifat fisis tanah asli Hambalang dapat dilihat pada Tabel 1 berikut :

Tabel 1. Sifat fisis tanah asli

\begin{tabular}{ll}
\hline Parameter & Nilai \\
\hline Kadar Air $(\omega)$ & $31,61 \%$ \\
Berat Jenis $(\mathrm{Gs})$ & 2,68 \\
Berat Volume $(\gamma)$ & $1,321 \mathrm{t} / \mathrm{m}^{3}$ \\
\hline
\end{tabular}

Menurut Das (1988), dengan nilai sifat fisis tanah seperti pada tabel diatas, tanah dapat diidentifikasikan sebagai tanah lunak.

Berdasarkan data hasil pengujian analisa saringan dan hidrometer, tanah lunak dapat dikelompokkan lagi dengan menggunakan sistem klasifikasi metode USCS dan AASTHO dibawah ini.

\section{USCS}

Klasifikasi tanah dengan metode USCS, sebagai berikut :

a. Lolos saringan no. $200=94,35 \%$. Tanah termasuk tanah berbutir halus.

b. Batas cari $(\mathrm{LL})=54,71 \%$ dan indeks plastisitas $(\mathrm{PI})=18,19 \%$. Tanah termasuk lanau atau lempung.

Dengan grafik hubungan batas cair dan indeks plastisitas untuk menentukan kelompok tanah
(Craig, 1991) pada Gambar 3, dapat diklasifikasikan tanah asli Hambalang termasuk kedalam kelompok klasifikasi $\mathrm{MH}$ atau lanau plastis.

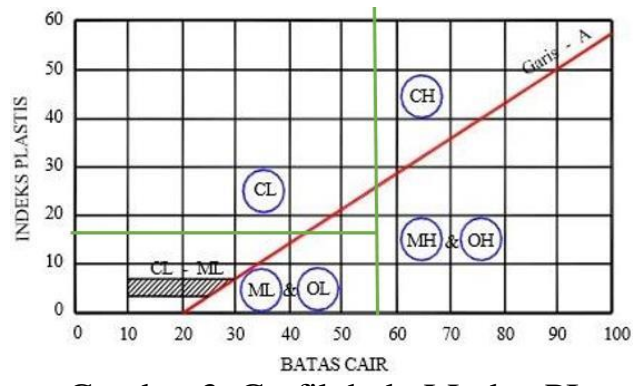

Gambar 3. Grafik hub. LL dan PI

\section{AASTHO}

Klasifikasi tanah dengan metode AASTHO sebagai berikut :

a. Lolos saringan no. $200=94,35 \%$. Klasifikasi tanah adalah lanau atau lempung.

b. Batas cari (LL) $=54,71 \%$ dan indeks plastisitas $(\mathrm{PI})=18,19 \%$. Klasifikasi tanah adalah A-7.

c. Karena nilai batas plastis (PL) $=36,51 \%$ > 30. Klasifikasi tanah adalah A-7-5.

d. Menurut Tabel 2 perbandingan sistem unified dengan AASTHO, A-7-5 dikelompokkan sebagai tanah $\mathrm{MH}$.

Tabel 2. Perbandingan sistem unified dan AASTHO

\begin{tabular}{|c|c|c|c|}
\hline \multirow{2}{*}{$\begin{array}{l}\text { Kelompok } \\
\text { tanah } \\
\text { Dalam Sis- } \\
\text { tem Unified }\end{array}$} & \multicolumn{3}{|c|}{$\begin{array}{l}\text { Kelompok tanah menurut sistem } \\
\text { AASTHO }\end{array}$} \\
\hline & $\begin{array}{l}\text { Paling } \\
\text { mungkin }\end{array}$ & Mungkin & $\begin{array}{l}\text { Mungkin } \\
\text { Tapi ja- } \\
\text { rang }\end{array}$ \\
\hline SM & $\begin{array}{l}\text { A-1-b, } \\
\text { A-2-4, } \\
\text { A-2-5, } \\
\text { A-2-7 }\end{array}$ & $\begin{array}{l}\text { A-2-6, } \\
\text { A-4, } \\
\text { A-5 }\end{array}$ & $\begin{array}{l}\text { A-6, } \\
\text { A-7-5, } \\
\text { A-7-6, } \\
\text { A-1-a }\end{array}$ \\
\hline SC & $\begin{array}{l}\text { A-2-6, } \\
\text { A-2-7 }\end{array}$ & $\begin{array}{l}\text { A-2-4, } \\
\text { A-6, } \\
\text { A-4, } \\
\text { A-7-6 }\end{array}$ & A-7-5 \\
\hline ML & $\begin{array}{l}\mathrm{A}-4 \\
\mathrm{~A}-4\end{array}$ & $\begin{array}{l}\text { A-6, } \\
\text { A-7-5 }\end{array}$ & - \\
\hline CL & $\begin{array}{l}\text { A-5, } \\
\text { A-7-6 }\end{array}$ & A-4 & - \\
\hline OL & $\begin{array}{l}\text { A-4, } \\
\text { A-5 }\end{array}$ & $\begin{array}{l}\text { A-6, } \\
\text { A-7-5, } \\
\text { A-7-6 } \\
\end{array}$ & - \\
\hline MH & $\begin{array}{l}\text { A-7-5, } \\
\text { A-5 }\end{array}$ & - & A-7-6 \\
\hline $\mathrm{CH}$ & A-7-6 & A-7-5 & - \\
\hline OH & $\begin{array}{l}\text { A-7-5, } \\
\text { A-5 }\end{array}$ & - & A-7-6 \\
\hline PT & - & - & - \\
\hline
\end{tabular}




\section{Penurunan Tanah Total (Sc)}

Tanah yang digunakan dalam pengujian, memiliki sifat-sifat mekanis seperti pada Tabel 3.

Tabel 3. Sifat mekanis tanah asli

\begin{tabular}{cccc}
\hline Jenis Pengujian & & Nilai & Satuan \\
\hline \multirow{2}{*}{ Direct Shear } & $\phi$ & 21,31 & $\circ$ \\
& $\mathrm{c}$ & 0,088 & $\mathrm{~kg} / \mathrm{cm}^{2}$ \\
\hline \multirow{2}{*}{ Triaxial $U U$} & $\phi$ & 12,485 & $\circ$ \\
& $\mathrm{c}$ & 0,194 & $\mathrm{~kg} / \mathrm{cm}^{2}$ \\
\hline \multirow{2}{*}{ Unconfined } & $\mathrm{qu}$ & 0,571 & $\mathrm{~kg} / \mathrm{cm}^{2}$ \\
Compression & $\mathrm{qu}$ & 0,5125 & $\mathrm{~kg} / \mathrm{cm}^{2}$ \\
& $\mathrm{St}$ & 1,118 & - \\
& $\mathrm{cu}$ & 0,2855 & $\mathrm{~kg} / \mathrm{cm}^{2}$ \\
\hline \multirow{2}{*}{ Consolidation } & $\mathrm{Cc}$ & 0,678333 & - \\
& $\mathrm{Cv}$ & 0,039657 & $\mathrm{~cm}^{2} / \mathrm{s}$ \\
\hline
\end{tabular}

Hasil dari pengujian konsolidasi tanah asli Hambalang, diperoleh grafik angka pori-log p. Dikarenakan tanah terkonsolidasi secara berlebihan (over consolidated), maka dicari nilai tekanan prakonsolidasi (pc') dengan cara yang disarankan Casagrande (1936) menggunakan grafik hubungan angka pori-log p (Das, 1988) seperti pada Gambar 4.

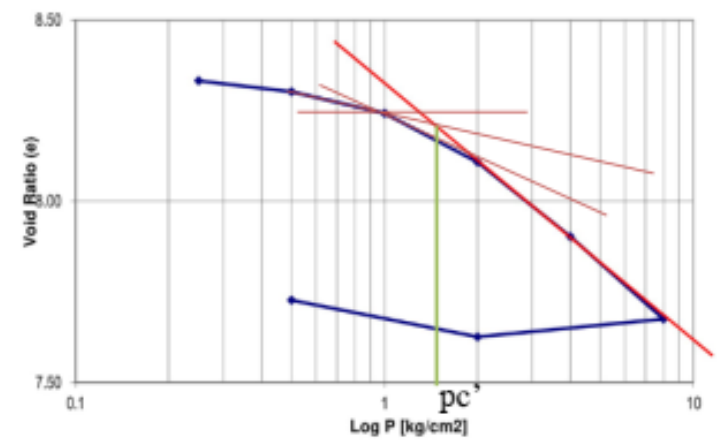

Gambar 4. Grafik angka pori-log $p$

Penelitian ini menggunakan tanah yang jenuh air (saturated). Pada tanah dengan keadaan saturated, berat volume tanah jenuh dapat ditentukan dengan persamaan sebagai berikut :

$\gamma_{s a t}=\frac{W}{V}=\frac{W_{s}+W_{\omega}}{V}=\frac{G_{s .} \gamma_{\omega}+e \cdot \gamma_{\omega}}{1+e}=\frac{\left(G_{s .}+e\right) \gamma_{\omega}}{V 1+e}(1)$

Pada tanah dengan kondisi jenuh, dihitung berat volume efektifnya $\left(\gamma^{\prime}\right)$ dengan persamaan berikut :

$\gamma^{\prime}=\gamma_{s a t}-\gamma_{\omega}$

Maka, dicari berat volume efektif tanah jenuh, dengan menggunakan persamaan (1) sebagai berikut

$\gamma_{s a t}=\frac{\left(G_{S}+e\right) \gamma_{\omega}}{V 1+e}=\frac{(2,68+1,427) 1}{1+1,427}$

$$
\begin{aligned}
\gamma_{s a t} & =1,692 \mathrm{gr} / \mathrm{cm}^{3} \\
\gamma^{\prime} & =\gamma_{s a t}-\gamma_{\omega} \\
& =1,692-1 \\
\gamma^{\prime} & =0,692 \mathrm{gr} / \mathrm{cm}^{3}
\end{aligned}
$$

Karena tanah terkonsolidasi secara berlebihan (overconsolidated), maka nilai swelling index (Cs) digunakan. Dimana nilai $\mathrm{Cs}$ memiliki persamaan berikut,

$C_{s}=\frac{1}{5}$ sampai dengan $\frac{1}{10} \cdot C_{C}$

Berdasarkan persamaan (3), maka digunakan nilai Cs sebagai berikut,

$$
\begin{aligned}
C_{S} & =\frac{1}{5} \cdot C_{C} \\
& =\frac{1}{5} \cdot 0,72=0,144
\end{aligned}
$$

Untuk menentukan persamaan penurunan total, besar tekanan di permukaan tanah adalah :

$$
\begin{aligned}
p o^{\prime} & =0,5 \cdot H \cdot \gamma^{\prime} \\
& =0,5 \cdot 50 \cdot 0,692 \\
p o^{\prime} & =17,305 \mathrm{gr} / \mathrm{cm}^{3} \\
\Delta p & =\text { ppasir. Hpasir } \\
& =1,532.20 \\
\Delta p & =30,64 \mathrm{gr} / \mathrm{cm}^{2} \\
p c^{\prime}= & \left.1,6 \mathrm{~kg} / \mathrm{cm}^{2} \text { (grafik angka pori-log } \mathrm{p}\right)
\end{aligned}
$$

Dikarenakan syarat yang dipenuhi adalah sebagai berikut,

$$
\begin{aligned}
& \left(p o^{\prime}+\Delta p\right)<p c^{\prime} \\
& \left(0,4795 \mathrm{~kg} / \mathrm{cm}^{2}\right)<1,6 \mathrm{~kg} / \mathrm{cm}^{2}
\end{aligned}
$$

Maka, untuk menghitung besar penurunan total (Sc) secara teoritis, persamaan yang digunakan adalah :

$$
\begin{aligned}
S_{c} & =\frac{C_{s} \cdot \Delta \mathrm{H}}{1+e_{0}} \cdot \log \left(\frac{p_{o}^{\prime}+\Delta p}{p_{O^{\prime}}}\right) \\
S_{c} & =\frac{0,144 \cdot 50}{1+1,427} \cdot \log \left(\frac{17,305+30,064}{17,305}\right) \\
S_{c} & =1,313 \mathrm{~cm}
\end{aligned}
$$

\section{Derajat Konsolidasi (U\%)}

Nilai derajat konsolidasi (U) yang diperoleh dari pemodelan di laboratorium dengan persamaan :

$U \%=\frac{\mathrm{St}}{S c}$

dimana

St $=$ Penurunan sesaat

$\mathrm{Sc}=$ Penurunan primer total 
Dengan besar penurunan pada waktu 96 jam (St) seperti pada Tabel 4 di bawah, didapatkan nilai derajat konsolidasinya.

Tabel 4. Derajat konsolidasi saat waktu 96 jam

\begin{tabular}{ccc}
\hline \multirow{2}{*}{ Variasi } & $\mathbf{S t}$ & \multirow{2}{*}{$\mathbf{U}$} \\
\cline { 2 - 2 } & $\mathbf{m m}$ & \\
\hline $50 \mathrm{~cm}$ & 6,27 & $47,75 \%$ \\
$40 \mathrm{~cm}$ & 6,25 & $47,58 \%$ \\
$30 \mathrm{~cm}$ & 4,91 & $37,40 \%$ \\
$20 \mathrm{~cm}$ & 4,47 & $34,06 \%$ \\
\hline
\end{tabular}

Perbedaan nilai U\% pada tiap variasi vertical drains dapat dilihat melalui grafik pada Gambar 5 berikut.

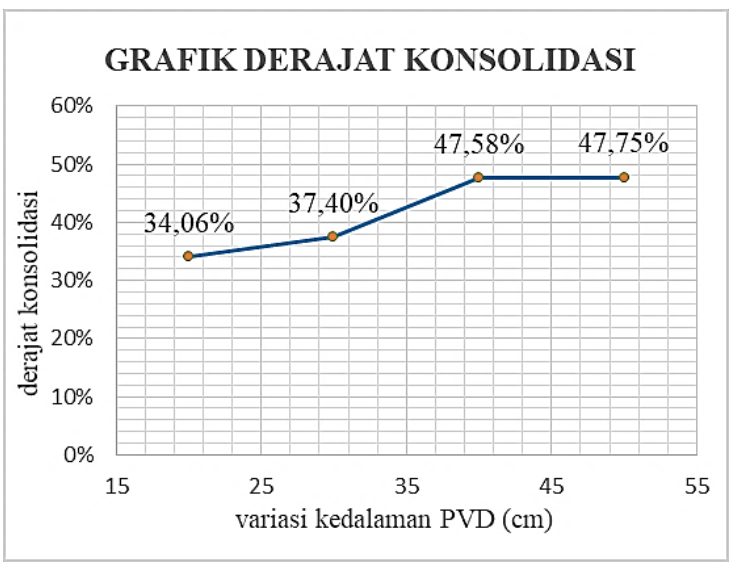

Sumber : Olahan pribadi

Gambar 5. Grafik perbedaan U\% tiap variasi

\section{Pengaruh Vertical drains}

Pemasangan vertical drains mempengaruhi lamanya waktu terjadinya konsolidasi. Terutama pada nilai Ch (Aspar, 2017). Berikut adalah nilai koefisien konslidasi arah vertikal (Cv) dan arah horizontal (Ch) dengan waktu konsolidasi selama 96 jam pada Tabel 5. Pada umumnya, nilai Ch dianggap 1 sampai $3 \mathrm{kali} \mathrm{Cv}$ (Mochtar, 2000). Digunakan nilai $\mathrm{Ch}=2 \mathrm{Cv}$.

Tabel 5. Koefisien konsolidasi pemodelan

\begin{tabular}{cccc}
\hline Variasi & Cv & Ch & Satuan \\
\hline $50 \mathrm{~cm}$ & 0,00017472 & 0,000349 & $\mathrm{~cm}^{2} / \mathrm{s}$ \\
$40 \mathrm{~cm}$ & 0,00017384 & 0,000348 & $\mathrm{~cm}^{2} / \mathrm{s}$ \\
$30 \mathrm{~cm}$ & 0,00012604 & 0,000252 & $\mathrm{~cm}^{2} / \mathrm{s}$ \\
$20 \mathrm{~cm}$ & 0,000112073 & 0,000224 & $\mathrm{~cm}^{2} / \mathrm{s}$ \\
\hline
\end{tabular}

Dilapangan, nilai derajat konsolidasi yang dibutuhkan supaya dapat dilakukannya pembangunan, yaitu U sebesar 90\%. Untuk mengetahui lamanya waktu konsolidasi yang dibutuhkan untuk mencapai U 90\%, digunakan persamaan waktu konsolidasi menurut Hansbo,
(1979), dengan menggunakan nilai Ch pemodelan yang diperoleh pada tabel 5 .

$t=\left(\frac{\mathrm{D}^{2}}{8 C_{h}}\right) \cdot 2 F(n) \cdot \ln \left(\frac{1}{1-U_{h}}\right)$

Didapatkan hasil untuk waktu konsolidasi mencapai U $90 \%$ pada pemodelan seperti pada Tabel 6 di bawah.

Tabel 6. Waktu konsolidasi saat U 90\%

\begin{tabular}{ccc}
\hline Variasi & t & Satuan \\
\hline $50 \mathrm{~cm}$ & 340 & jam \\
$40 \mathrm{~cm}$ & 342 & jam \\
$30 \mathrm{~cm}$ & 472 & jam \\
$20 \mathrm{~cm}$ & 531 & jam \\
\hline
\end{tabular}

\section{SIMPULAN}

Hasil pengujian sifat fisis tanah asli Hambalang diklasifikasikan dengan metode USCS tanah termasuk $\mathrm{MH}$ dan sistem AASTHO tanah termasuk A-7-5. Menurut teoritis, tanah lunak tersebut memiliki nilai penurunan total $(\mathrm{Sc})$ sebesar $1,131 \mathrm{~cm}$. Pada penelitian ini, diperoleh besar penurunan tanah pemodelan pada waktu preloading 96 jam (St) yang kemudian dibandingkan dengan besar penurunan total (Sc), sehingga dapat diperoleh nilai derajat konsolidasi (U) pada kedalaman pemasangan vertical drains $50 \mathrm{~cm}, 40 \mathrm{~cm}, 30 \mathrm{~cm}$, dan $20 \mathrm{~cm}$ adalah $47,75 \%$; 47,58\%; 37,40\%; dan 34,06\%. Dapat disimpulkan bahwa semakin dalam pemasangan vertical drains, maka semaiki besar nilai derajat konsolidasi yang dicapai.

\section{UCAPAN TERIMAKASIH}

Ucapan terimakasih saya sampaikan kepada pihak BTAM, berkat dana bantuan yang telah diberikan, penelitian kami dapat berlangsung dengan lancar sampai selesai.

\section{DAFTAR PUSTAKA}

Aspar, Wimpie A.N., dkk., 2017. Perhitungan Kembali Nilai Koefisien Konsolidasi pada Perbaikan Tanah Lempung Lunak. Institut Sains Teknologi Al-Kamal.

Craig, R. F., 1991. Mekanika Tanah. Jakarta: PT. Erlangga.

Das, Braja M., (1988). Mekanika Tanah (Prinsipprinsip Rekayasa Geoteknis). Terjemahan oleh Noor Endah \& Indrasurya B. Mochtar. Jilid I. Jakarta: Erlangga 
Dian Utami, dkk., 2018. Desain Prefabricated Vertical drains (PVD) pada Rencana Pembangunan Depo Kontainer di Kawasan Berikat Nusantara (KBN), Cakung-Clincing, Jakarta Utara. Fakultas Teknik, Universitas Hasanuddin.

Fathurrozi, Rezqi, F., 2016. Sifat-sifat Fisis dan Mekanis Tanah Timbunan Badan Jalan Kuala Kapuas. Politeknik Negeri Banjarmasin.

Gunawan, Sumiyati, 2014. Percepatan Penurunan Sampah Plastik sebagai Drainase Vertikal. Universitas Atam jaya Yogyakarta.

Hansbo, S. "Consolidation of Clay by BandShaped Prefabricated Drains," Ground Engineering, 1979 Vol. 12, No. 5, hal.16-25.

Juniarto., 2011. Analisa Waktu Penurunan Tanah dengan Kombinasi Metode Preloading dan Prefabricated Vertical drains (PVD) antara Pola Segitiga dan Persegi pada Perbaikan Tanah. Universitas Gunadarma.
Mochtar, Indrasurya B., 2000. Teknologi Perbaikan Tanah dan Alternatif Perencanaan pada Tanah Bermasalah (Problematic Soils).

Pratama, D.R., dkk., 2015. Perilakum Penurunan Tanah terhadap Dry Side of Optimum dan Wet Side of Optimum pada Kepadatan Tanah Organik. Lampung: Universitas Lampung.

Puspita, N., Capri, A., 2017. Analisa Penurunan Tanah Lunak dengan Beberapa Metode Konsolidasi pada Proyek Jalan Tol Palindra. Universitas Indo Global Mandiri (UIGM).

Suroso, dkk., 2008. Alternatif Perkuatan Tanah Lempung Lunak (Soft Clay) Menggunakan Cerucuk dengan Variasi Panjang dan Diameter Cerucuk. Universitas Brawijaya Malang. 